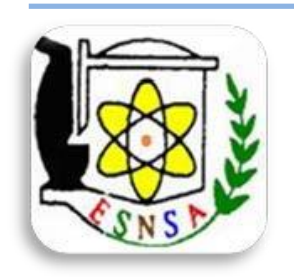

Arab Journal of Nuclear Sciences and Applications

ISSN 1110-0451

Web site: ainsa.journals.ekb.eg

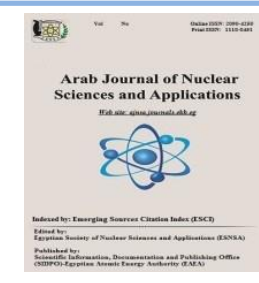

(ESNSA)

\title{
High Borated Stainless Steel Alloys for Nuclear Reactor Domains
}

\author{
Shaimaa Hafez ${ }^{(1)}$, R. M. Elshazly ${ }^{(2)}$, M. M. Eissa ${ }^{(3)}$, S. U. El-Kameesy ${ }^{(4)}$ \\ ${ }^{(1)}$ Basic \& Applied sciences Department, Faculty of Energy \& Environmental Engineering, British University in Egypt, \\ Cairo, Egypt \\ (2) Physics Department, Faculty of Science, Al-Azhar University, Cairo, Egypt \\ (3) Steel Technology Department, Central Metallurgical Research and Development Institute \\ (CMRDI), Helwan, Egypt \\ ${ }^{(4)}$ Physics Department, Faculty of Science, Ain Shams University, Cairo, Egypt
}

Austenitic stainless steel industry in the nuclear domain still needs further progress for better performance, quality and safety for being the major construction nuclear materials of different components of nuclear reactors. One grade of stainless steel with fundamental composition of SS316 and another having B (SS316B) were designed. The macroscopic cross sections for neutrons were carried out by ${ }^{241} \mathrm{Am}-\mathrm{Be}$ neutron source, the results confirmed that borated stainless steels fulfill the requirements of having a proper shielding material that achieves the necessary safety conditions. Samples of the modified steels were subjected to microstructure examination, hardness, impact and tensile testing. In addition, the corrosion behavior of the modified steels in $3.5 \mathrm{wt} \% \mathrm{NaCl}$ medium was examined. The microstructure observation showed mainly an austenitic phase in all the modified steels. Using the scanning electron microscope in conjunction with EDX technique, a secondary phase of a different morphology and size was observed at the austenitic matrix of the other studied steel. Certainly, this change is mainly attributed to form a carbide element as boron. The investigated steel alloys containing B showed of a lower corrosion rate and higher mechanical properties than the standard alloy.

Keywords: Construction Nuclear Materials, Borated Stainless Steel Alloys, Attenuation, Mechanical and Structural Parameters

\section{Introduction}

Nuclear power reactors are characterized by high radiation field's existence; high temperature and the requirement of materials that possess special properties. The radiation fields and high temperature have a profound effect on the properties of the structural materials. The nuclear reactor materials must meet the specifications of strength and reliability. The needs of quality control on each component to be used in the nuclear reactor sectors are very significant and are critical to their safe and efficient usage. Currently, new designs for nuclear reactors are coming forward and some of them are in operation because the first generation reactors come to the end of their operating lives [1-3]. In the field of design and construction of nuclear reactors, reactor structural materials play a very important role for a safe, reliable and economic operation of nuclear power plants $[2,4]$. Nuclear reactors materials are used in encounter hostile environment and aggressive medium during service, and are expected to possess their structural and metallurgical integrity over a long time of their use [5].

The effect of radiation on embrittlement, corrosion, radiation induced growth, stress corrosion cracking, hydrogen and helium embrittlement, hardness and ductility are the major challenges of reactor materials [4-5]. In order to

Corresponding author: shaimaa.hafez@bue.edu.eg

DOI: 10.21608/ajnsa.2021.29519.1352

(C) Scientific Information, Documentation and Publishing Office (SIDPO)-EAEA 
realize a high degree of reliability and at the same time meet the imposing challenges, material specifications and acceptance criteria are extremely rigorous and the products have to subject to a detailed testing and characterization prior to their use [4-5].

Now, it is important to produce reactor structural materials that resist the hard condition irradiation environment and high temperatures to support rapid combustion. [6].

The best structural material for power reactor components is stainless steel (SS). Stainless steel alloys meet the desirable conditions because of cost, availability and manufacturing specifications. Austenitic stainless steels are the most common material used in the core of the nuclear power reactors [7-8].

One of the most important absorbed elements used in neutron shielding materials as the storage of spent nuclear fuel, reactor shielding, nuclear waste disposals, castor transport vessels and fuel shipment containers is Boron [9]. Besides the beam attenuation characteristics of shielding materials, they have to be corrosion resistant under harsh conditions. In castor transport vessels, neutrons are slowed down to thermal energy by the interaction with moderator material (e.g. graphite or hydrogenous materials) and then captured by boron alloyed steels. Similarly, lead, iron or concrete are used for attenuation of gamma rays [9].

\section{Material and Methods}

\section{Sample preparation}

To produce borated austenitic stainless steels with a fundamental composition of SS316, a series of experiments were performed. Hence the different molten stainless steels were prepared by melting stainless steel scrap, and ferroalloys, ferroboron, and or ferrotitanium in medium frequency induction furnace with magnesite crucible capacity. After full killing of molten stainless steel with aluminum, the molten metal was poured into metal mold with $70 \mathrm{~mm}$ inner diameter. Afterward, the prepared ingots were hot forged into bars to reach a final cross section of 30 x $300 \mathrm{~mm}^{2}$. The produced bars were solution treated at $1323 \mathrm{~K}$ for $30 \mathrm{~min}$ and then all were quenched by water. The steel alloys were prepared at the Central Metallurgical Research and Development Institute (CMRDI), Cairo, Egypt.

The produced alloys compositions were specified using spectrographic analysis (SPGA). The obtained results are shown in Table (1). Measurement of the total boron content in the prepared stainless steels alloys was undertaken using ICP-OES Optima 2000 DV Perkin Elmer.

\section{Experimental Details}

\section{Attenuation testing}

The ${ }^{241} \mathrm{Am}-\mathrm{Be}$ neutron source with neutron yield $=(1.1-1.4) * 10^{7} \mathrm{n} / \mathrm{s}$ and activity $100 \mathrm{mCi}$ and $\mathrm{BF}_{3}$ neutron detector were used in the present work. The former was used to detect the total slow, slow and neutrons $\left(E_{n} \geq 10 \mathrm{keV}\right)$, the Source was kept constant at $7 \mathrm{~cm}$ distance from the detector. A sheet of Polyethylene material $(6 \mathrm{~cm} \times 6 \mathrm{~cm})$ was used to obtain slow neutrons while boron carbide sheets were used to obtain fast neutrons $\left(E_{n} \geq 10\right.$ $\mathrm{keV}$ ).

The gamma ray attenuation parameters of the prepared stainless steel samples were measured for several gamma transitions obtained from $^{232} \mathrm{Th}$ source $(238.63,338.28,583.19,911.2$ and 2614.51 $\mathrm{keV})$. The measurements were performed using $\mathrm{NaI}(\mathrm{Tl})$ detector.

A comparison between the experimental and the corresponding theoretical attenuation parameters was performed using the WinXCom computer program (Version 3.1) [6,19] for the stainless steel samples.

The linear attenuation coefficient maximum experimental error resulting from intensities $\mathrm{I}_{0}, \mathrm{I}$ and thickness of the samples respectively can be calculated from the following formula:

Table (1): Chemical composition of the modified stainless steel samples

\begin{tabular}{|c|c|c|c|c|c|c|c|c|c|c|c|c|c|c|c|c|}
\hline \multirow{2}{*}{$\begin{array}{l}\text { Steel } \\
\text { Code }\end{array}$} & \multicolumn{16}{|c|}{ Chemical Composition, wt \% } \\
\hline & $\mathrm{C}$ & $\mathrm{Si}$ & $\mathrm{Mn}$ & $\mathrm{P}$ & S & $\mathrm{Cr}$ & $\mathrm{Ni}$ & Mo & $\mathrm{W}$ & $\mathrm{Cu}$ & $\mathrm{Ti}$ & $\mathrm{V}$ & $\mathrm{Al}$ & $\mathrm{N}$ & $\mathrm{B}$ & $\mathrm{Fe}$ \\
\hline $\operatorname{SS316}^{[17]}$ & 0.05 & 0.41 & 0.48 & 0.018 & 0.015 & 16.19 & 12.92 & 2.40 & 0.02 & 0.12 & 0.005 & 0.10 & 0.040 & 0.0330 & 0.0025 & 66.96 \\
\hline SS316B & 0.06 & 0.48 & 0.66 & 0.020 & 0.021 & 16.30 & 12.30 & 2.53 & 0.01 & 0.11 & 0.003 & 0.07 & 0.010 & 0.0314 & 0.2400 & 67.18 \\
\hline
\end{tabular}




$$
\Delta \mu=\frac{1}{x} \sqrt{\left(\frac{\Delta I_{0}}{I}\right)^{2}+\left(\frac{\Delta I}{I}\right)^{2}+\left(\ln \frac{I_{0}}{I}\right)^{2}\left(\frac{\Delta x}{x}\right)^{2}}
$$

Where $\Delta \mathrm{X} \Delta \mathrm{I}_{0}$, and $\Delta \mathrm{I}$ are the errors of the thickness of the samples and the intensities Io, I respectively [11].

\section{Corrosion rate testing}

Cyclic anodic polarization technique was used to measure the corrosion rate of the modified steel alloys. The samples were glossed to a 1200-grit finish, ultrasonically cleaned and then rinsed with ethanol and finally dried. A Pt counter electrode was used with a conventional three-electrode cell in a single compartment-cylindrical glass cell. All the potentials were measured with respect to a saturated calomel electrode (SCE) reference electrode at $25{ }^{\circ} \mathrm{C}$. A computerized Potentiostat / Galvanostat (Autolab PG STAT 30) is used, a medium of sodium chloride was prepared from analytical grade chemicals and bidistilled water. The cyclic anodic polarization measurement was performed from $-0.3 \mathrm{~V}$ below $\mathrm{E}_{\text {corr }}$ in the positive direction $\left(\approx 1 \mathrm{~V}\right.$ above $\left.\mathrm{E}_{\text {corr }}\right)$ and then reverses scan direction until $\mathrm{E}_{\text {corr }}$.

\section{Metallography}

Multiple procedures were operated to prepare the chosen austenitic steel samples in the present work plan. These procedures were completed in the following steps:

\section{Step 1: Sectioning}

All steels were cut into pieces from the prepared parent metal using an ISOMET-TM low speed saw to achieve minimum plastic deformation during cutting process.

\section{Step 2: Polishing}

The next preparation step of steel samples was polishing, to obtain a flat, scratch free and likemirror steel surface. At the beginning of polishing, another abrading step was performed for steel surface using meshes from 600 to 2500 number. Then the specimen was held mechanically by hand to start the mechanical polishing process on the top of the laps having the rotation motion. The process was done by Alumina Micro polish suspensions 0.3 and 0.1 microns and warm running water was used to wash and swab the samples. At the end of polishing step, all samples were immersed in an alcohol bath and cleaned using an ultrasonic device for 15 minutes then swabbed by tissue paper.
Step 3: Etching

To distinguish the morphology of the treated steel, all treated steel samples were electro etched using oxalic acid (20\%) solution, 1.8 Volt, 1Amp.

\section{Mechanical testing \\ Hardness measurements}

Samples of $\left(\begin{array}{llllllll}1.5 & \mathrm{~cm} & \mathrm{x} & 1.5 & \mathrm{~cm} & \mathrm{x} & 0.4 & \mathrm{~cm}\end{array}\right)$ dimensions were properly ground to give a flat and stable surface using a hand grinder. Thereafter, HRB hardness measurements were performed using Rockwell (Fr-3el) hardness tester machine of $10 \mathrm{Kg}$ working load applied for 10 seconds using a diamond indenter with $136^{\circ}$ included angle. The average of three independent indentations was used as a hardness value.

\section{Tensile properties measurements}

Round tensile samples were machined with dimensions according to ASTM-E8 specification. Testing was performed using tensile machine (Shimadzu, $20 \mathrm{KN}$ ) at room temperature with a cross head speed of $0.3 \mathrm{~mm} / \mathrm{min}$. The average of two tensile tests data was receded for each tensile parameter. The stress/strain curves were provided as a computer output by the control unit of the testing machine.

\section{Impact energy measurements}

The absorbed impact energy was measured using a Charpy-V/Izod impact tester through a mechanical dial. The impact test was performed on PKP450 impact testing machine. The dimension of the sample was $(1.0 \mathrm{~cm} \times 1.0 \mathrm{~cm} \times 5.5 \mathrm{~cm})$.

\section{Results and Discussion \\ Attenuation properties \\ Neutrons attenuation}

The attenuation parameters of the present developed austenitic stainless steel samples for neutrons of energies higher than $10 \mathrm{keV}$, slow and total slow neutrons were determined from which the corresponding macroscopic neutron cross sections were evaluated and presented in Table (2).

From Table (2), it was found that the lowest values of neutron macroscopic cross-section were

Table (2): The neutron macroscopic cross sections for the produced alloys

\begin{tabular}{lccc}
\hline Steel Code & $\begin{array}{c}\sum_{\mathbf{N}>10 \mathrm{keV}} \\
\left(\mathbf{c m}^{-1}\right)\end{array}$ & $\sum_{\mathfrak{t}}\left(\mathbf{c m}^{-\mathbf{1}}\right)$ & $\sum \mathbf{s}\left(\mathbf{c m}^{-\mathbf{1}}\right)$ \\
\hline \multirow{2}{*}{$\mathbf{S S 3 1 6} \mathbf{6}^{[17]}$} & $0.0280 \pm$ & $0.0623 \pm$ & $0.0405 \pm$ \\
& 0.0033 & 0.0070 & 0.0048 \\
\hline \multirow{2}{*}{$\mathbf{S S 3 1 6 B}$} & $\begin{array}{c}0.0270 \pm \\
0.0023\end{array}$ & $\begin{array}{c}0.0680 \pm \\
0.0034\end{array}$ & $\begin{array}{c}0.0591 \pm \\
\end{array}$ \\
\hline
\end{tabular}


measured for neutrons filtered by born carbide $\left(\sum \mathrm{N}>10 \mathrm{keV}\right)$. This behavior of that type of neutrons may be attributed mainly to inelastic scattering $(\mathrm{n}, \mathrm{n})$ reactions with $\mathrm{Fe}$ and Mo nuclei; onn were about 118 and 113 barns respectively [20]. While the highest values of neutrons macroscopic cross-section were for total slow neutron $\sum \mathrm{t}$ (primary slow as well as slowdown in the studied alloys), this behavior may be attributed to the competition between absorption process (elastic scattering of slow neutron with $\mathrm{B}$ nuclei; ( $\sigma \mathrm{n} \gamma$ was about 750 barn $(\mathrm{n}, \gamma)$ reaction [20]) and slow down process (inelastic scattering $(\mathrm{n}, \mathrm{n})$ reactions with $\mathrm{Fe}$ and Mo nuclei ) which took place in the case of total slow neutron. However, in the case of neutron with energy greater than $10 \mathrm{keV}$, the only slow down process that appeared. (Note that, about 23\% of neutron energies obtained from $241 \mathrm{Am}-\mathrm{Be}$ neutron source was considered slow neutron).

It was found that the modified stainless steel alloys SS316B have a higher macroscopic cross sections value than the standard sample SS316 of slow and total slow neutrons. On the other hand, the borated stainless steel alloy SS316B has a lower macroscopic cross sections value than the standard sample SS316 of neutrons of energy $>10$ $\mathrm{keV}$.

Because of the high neutron absorption of boron compared to steel, the neutron radiography was a muscular tool for the nondestructive consideration. The most important industrial needs for the shielding materials were the capability of the absorbing material over the whole volume and maximum thermal neutron absorption ability to perform the required safety purposes [12].

\section{Gamma rays' attenuation}

The linear shielding parameters were used to evaluate the experimental mass attenuation coefficients $(\sigma \mathrm{Exp})$ that were experimentally obtained for different five gamma ray energies. Figure (1) showed the dependence of the mass attenuation coefficient on the energy of the incident gamma ray. A comparison with the corresponding computational mass attenuation coefficients $(\sigma \mathrm{Theo})$ obtained using the WinXCom computer program is also given in the same Figure. A clear agreement was obtained between them.
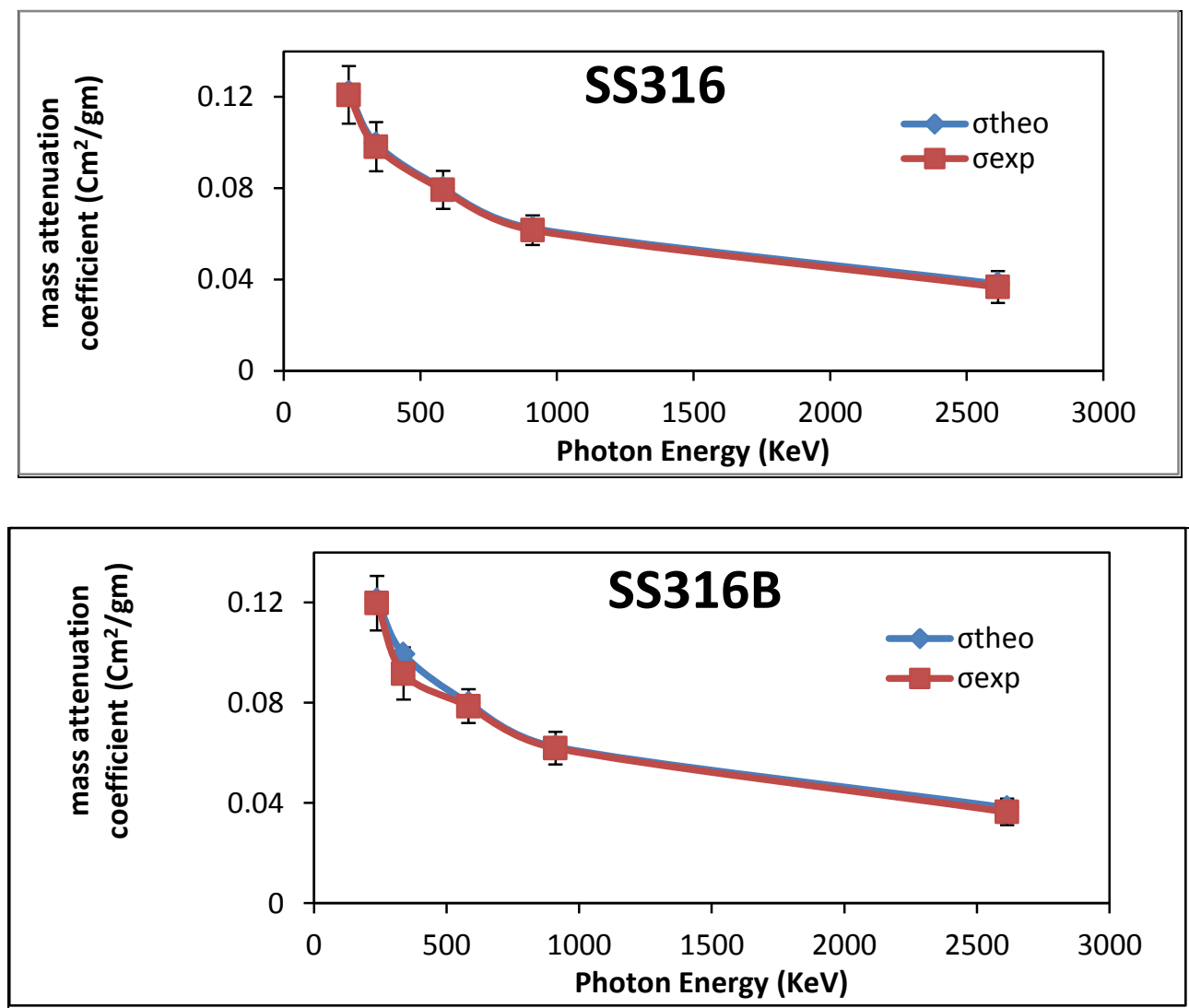

Fig. (1): Experimental and computational mass attenuation coefficients of the modified alloys 
Moreover, the results shown in Figure (1) proved that the changes in the mass attenuation coefficients were extremely small. The reason for that was the very small difference between the densities of all the investigated steel samples [21].

\section{Corrosion rate}

The corrosion rates in $\mathrm{mm} / \mathrm{y}$ in $3.5 \mathrm{w} . \mathrm{t} \%$ of the investigated stainless steel alloys were illustrated in Table (3) and Figure (2). The obtained data indicated that the borated stainless steel (SS316B) has corrosion rates lower than the conventional SS316 steel samples.

Table (3): Corrosion rate of the modified steels in 3.5w.t\% $\mathrm{NaCl}$ solution

\begin{tabular}{lc}
\hline Steel Code & Corrosion Rate, $\mathbf{~ m m} / \mathbf{y}$ \\
\hline SS316 $^{[17]}$ & 0.09410 \\
\hline SS316B & 0.0140 \\
\hline
\end{tabular}

The superiority of the borated stainless steels was based on the presence of the secondary phase which prevented attacking the grain boundaries [8].

\section{Microstructure}

It is well known that the solution treatment must have been applied to austenitic stainless steel before application [13, 14]. It consisted of annealing the steel at $1050^{\circ} \mathrm{C}$, followed by rapid quenching in water to dissolve all carbides (secondary phase) into the austenite matrix, obtaining austenite structure as the dominant phase. Microstructure of SS316 steel represented a good example for this process. The microstructure of the investigated steel SS316 was represented by austenite as a domain phase with a few fractions of carbides.

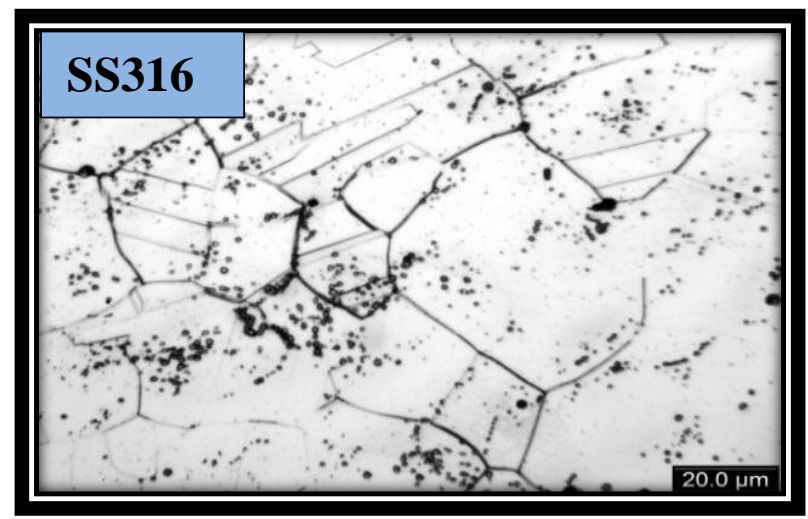

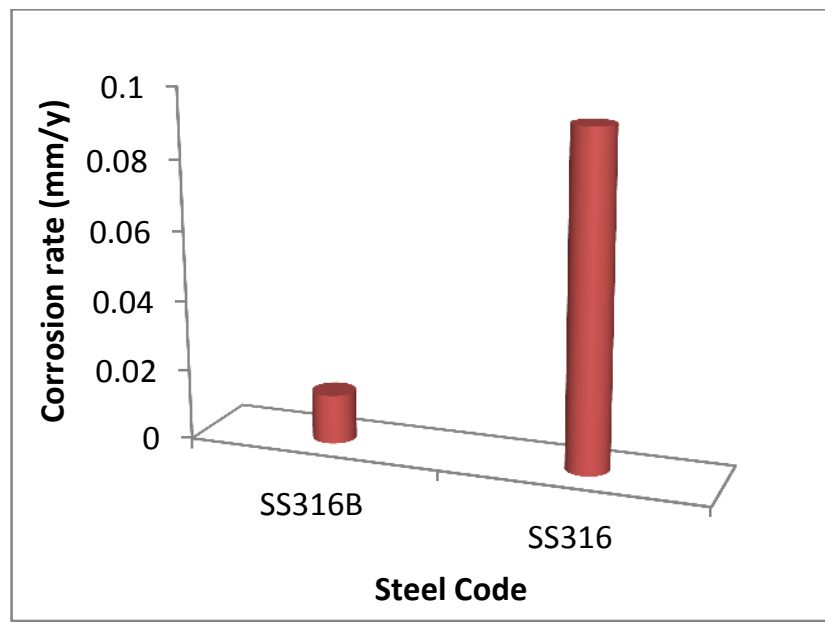

Fig. (2): Corrosion rates of the modified steels in 3.5w.t\% NaCl solution

At the meantime, secondary phase was observed with different morphology and size at the austenite matrix of the other studied steel. Certainly, this change was mainly attributed to a carbide forming element as boron [18].

A very large number of twins was appeared in the optical micrographs of the investigated samples as shown in Figure (3) which illustrates the fully austenite phase of them.

As mentioned before, new phase has been observed throughout the austenite matrix in SS316 B. This new phase has a non-uniform morphology with large size. This phase is stable either in as cast condition, or after solution treatment. This reflects that this phase was formed at the solidification regime at a high temperature [15]. As discussed before, boron is insoluble alloying element in the austenite. In addition, boron can form boron carbides or nitrides regarding to their less free energy to form at a high temperature. It is worthy noticed that the new phase well distribute throughout the matrix. Certainly, this means that

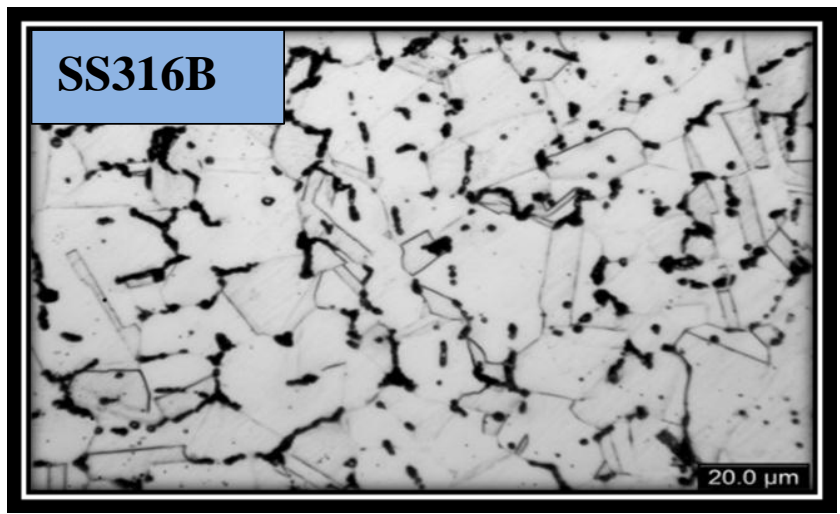

Fig. (3): Microstructure of the investigated stainless steel 
this phase was formed at a high temperature before the austenite dendrite formation, and consequently before the austenite boundaries.

Using scanning electron microscope with conjugation with EDX technique, it was found that boron was enriched with chromium in eutectic structure dispersed throughout the austenite matrix. The new eutectic allegation was confirmed by EDX analysis of several sites in the austenite matrix as shown in Figure (4). Boron is insoluble alloying element in austenite was confirmed, where the austenite matrix analysis refers to its being free of boron [16]. At the meantime, the chemical composition of the new eutectic phase refers to heterogeneous nucleation occurred between $\mathrm{B}_{4} \mathrm{C}$ and $\mathrm{Cr}_{2} \mathrm{C}_{3}$, which should be attributed to the low lattice misfit between the two carbides.

\section{Mechanical properties}

To estimate the effect of boron content on the prepared stainless steel alloys, it was necessary to measure the mechanical properties as Vickers hardness, yield strength, ultimate tensile strength, and elongation, reduction of area and impact energy. The obtained data are given in Table (4).

From the results given in Table (4), it was found that the produced austenitic stainless steels containing B (SS316B) showed a higher hardness, ultimate tensile strength, elongation and impact energy as compared to the standard SS316 steel, this strengthening was joined with decreasing the ductility (reduction of area) and the yield strength of the borated stainless steel alloys.

The strengthening effect of B could be assigned to the solution hardening and precipitation of these elements as strong carbide or nitride formers. The higher B content enhanced the formation of intermetallic compounds and reduced the ductility.

The better tensile and impact properties of the proposed alloys can be used in fillet welds and lap joints where the positioning of base plates helps to

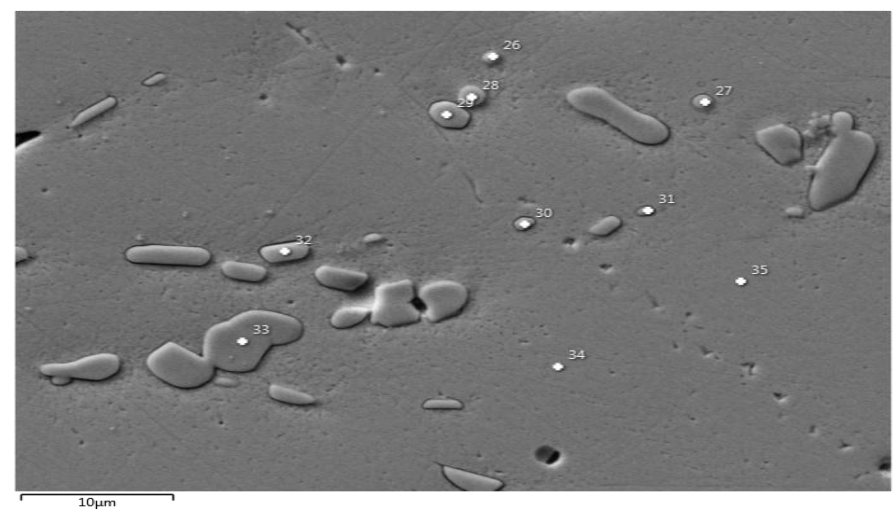

\begin{tabular}{|l|c|c|c|c|c|c|c|c|c|c|}
\hline Spectrum & Spectrum. & Spectrum. & Spectrum. & Spectrum. & Spectrum. & Spectrum. & Spectrum. & Spectrum. & Spectrum. & Spectrum. \\
name & $\mathbf{2 6}$ & $\mathbf{2 7}$ & $\mathbf{2 8}$ & $\mathbf{2 9}$ & $\mathbf{3 0}$ & $\mathbf{3 1}$ & $\mathbf{3 2}$ & $\mathbf{3 3}$ & $\mathbf{3 4}$ & $\mathbf{3 5}$ \\
\hline $\mathrm{B}$ & 12.46 & 10.53 & 10.21 & 8.02 & 8.77 & 6.20 & 11.09 & 8.38 & 0.00 & 0.00 \\
\hline $\mathrm{C}$ & 5.83 & 4.76 & 3.94 & 4.83 & 5.17 & 5.11 & 5.50 & 4.28 & 4.37 & 4.21 \\
\hline $\mathrm{Al}$ & 0.05 & 0.01 & 0.04 & 0.03 & 0.00 & 0.01 & 0.05 & 0.00 & 0.00 & 0.02 \\
\hline $\mathrm{Si}$ & 0.22 & 0.19 & 0.07 & 0.07 & 0.11 & 0.08 & 0.11 & 0.02 & 0.45 & 0.34 \\
\hline $\mathrm{S}$ & 0.98 & & & & & & & & 0.85 & 1.31 \\
\hline $\mathrm{V}$ & & & & & 0.25 & & & & & \\
\hline $\mathrm{Cr}$ & 30.07 & 32.83 & 49.34 & 52.63 & 52.62 & 51.28 & 48.68 & 49.63 & 14.98 & 15.51 \\
\hline $\mathrm{Mn}$ & 0.67 & 0.38 & 0.50 & 0.43 & 0.41 & 0.56 & 0.20 & 0.63 & 0.66 & 0.67 \\
\hline $\mathrm{Fe}$ & 44.08 & 42.95 & 30.99 & 28.80 & 28.22 & 31.78 & 28.92 & 31.48 & 63.30 & 64.39 \\
\hline $\mathrm{Ni}$ & 5.63 & 5.22 & 1.06 & 0.74 & 0.71 & 1.26 & 0.83 & 0.93 & 13.12 & 13.55 \\
\hline $\mathrm{Mo}$ & & 3.11 & 3.85 & 4.46 & 3.75 & 3.72 & 4.62 & 4.64 & 2.27 & \\
\hline $\mathrm{Gesamt}$ & 100.0 & 100.0 & 100.0 & 100.0 & 100.0 & 100.0 & 100.0 & 100.0 & 100.0 & 100.0 \\
\hline
\end{tabular}

Fig. (4): SEM and EDX analysis of SS316B steel alloy 
prevent the seeping of the neutrons through weld metal [9].

\section{Conclusion}

One grade of steel with fundamental composition of SS316 in addition B (SS316B) was produced, studied and compared with a standard SS316 austenitic stainless steel prepared in the same conditions as candidate materials for nuclear reactor domain. The developed steels revealed austenitic microstructure and exhibited lower corrosion rate compared with the standard SS316 steel. The modified austenitic stainless steels included B exhibited a higher hardness, ultimate tensile strength, elongation and impact energy as compared to the standard SS316 steel, this strengthening was assigned with reduction of ductility (reduction of area) and the yield strength of borated stainless steel alloys.

The macroscopic cross sections of total slow, neutrons $(\mathrm{E}>10 \mathrm{keV})$ and slow neutrons for the modified boron stainless steel were compared with the standard SS316 stainless steel. The developed B stainless steels alloy (SS316B) has higher macroscopic cross section value than the standard SS316 steel of slow and total slow neutrons. On the other hand, the borated stainless steel alloy SS316B has a lower macroscopic cross section value than that of the standard sample SS316 of neutrons with energy $>10 \mathrm{keV}$. All the studied alloys nearly have the same values for the mass attenuation coefficients of gamma ray. The good mechanical properties, corrosion resistance as well as attenuation properties of the developed boron stainless steel alloy made it a nominee material for nuclear reactor domain.

\section{References}

1. Lherbier, L., (July 2012) Technical Paper: Solving Nuclear Storage Issues, nuclear exchange, 34.

2. Robert, S. B. (1991) Borated Stainless Steels (ASTMA887-88) a Comparison of Grade ANeutrosorb Plus, and Grade B- Neutrosorb, Application Engineering, carpenter technology Corporation, 657.

3. Marmy, P. (2000) Titanium Alloys Irradiation Testing, Report on ITER TASK BL 14.2, 6.

4. David, V.F., John, C.E., Landa, L.W. and Raul, B.R. (2004) General and Localized Corrosion of Austenitic and Borated Stainless Steels in Simulated Concentrated Ground Water, proc American society of mechanical engineers' pressure vessels and piping division (ASME-PVP) conference in San Diego, CA 25-29.

5. Victoria, M., Baluc, N. and Spätig, P. (2001) Structural Material for Fusion Reactors. EPFLCRPP Fusion Technology Materials, CH-5232 Villigen PSI, Switzerland.

6. Gerward, L., Guilbert, N., Jensen, K.B. and Leving, H. (2004) WinXCom - A Program for Calculating X-Ray Attenuation Coefficients, Radiation Physics and Chemistry, 71, 653654.

7. Bastu“rk, M., Arztmann, J., Jerlich, W., Kardjilo, N., Lehman, E. and Zawisky, M. (2005) Analysis of Neutron Attenuation in Boron-Alloyed Stainless Steel with Neutron Radiography and JEN-3 Gauge, Journal of Nuclear Materials, 341, 189-200.

8. Moreno, D.A., Molina, B., Ranninger, C., Montero, F. and Izquierdo, J. (2004) Microstructural Characterization and Pitting Corrosion Behavior of UNS530466 Borated Stainless Steel, Corrosion, 60, 6-573.

9. Hänninen, H. (2009) Material Development in New Reactor Designs -Gen III and SCWR Concept, 20th International Conference on Structural Mechanics in Reactor Technology (SMIRT), August 9 14, Dipoli Congress Centre, Espoo, Finland.

10. Sears, V.F. (1992) Neutron Scattering Lengths and Cross-Sections, Neutron News, 3(3), 26.

11. Walker, S. J. (2000) Permissible Dose, A History of Radiation Protection in the Twentieth Century, University of California Press

12. Bastürk, M., Arztmann, J., Jerlich, W., Kardjilo, N., Lehman, E. and Zawisky, M. (2005) Analysis of Neutron Attenuation in Boron-Alloyed Stainless Steel with Neutron Radiography and JEN-3 Gauge, Journal of Nuclear Materials, 341, 189-200.

13. Yoshihara, K., and Kazuyoshi, N. (1982) The Precipitation Behavior of Titanium Carbide on the Surface of SUS 321 Stainless Steel, Journal of the Japan Institute of Metals and Materials, 46(10), 963-972.

14. Mangour, B. A., Seok, M., Dariusz, B., Grzesiak, and Lee, K. A. (2018) Strengthening of Stainless Steel by Titanium Carbide Addition and Grain Refinement During Selective Laser Melting, Materials Science and Engineering: A, 17, 812-818. 
15. Schimdt, H. J. G. (1971) Effect of Boron Additions to Austenitic Stainless Steels-Part1, Journal the iron and steel institute, 209(11), 900-909.

16. Balakrishnan, N., and Rajesh, Dr. R. (2018) Fabrication and Analysis of 304 Stainless Steel Boron Carbide Metal Matrix Composite, International Journal of Mechanical Engineering and Technology (IJMET), 9(5), 33-42, May.

17. Shaimaa Hafez, Essia, M.M., EL-Kameesy, S.U., EL-Shazly, R.M., EL-Fawkhry, M.K. and Aly Saeed (2018) Modified BoronTitanium Austenitic Stainless Steel Alloys for Power Reactors, International Journal of Engineering Technologies and Management Research, 5(6).

18. Kumar G. R., Ram G. D. J. and Rao S. R. K. (2015) Microstructure and Mechanical Properties of Borated Stainless Steel (304B)
GTA and SMA Welds, La Metallurgia Italian $-n, 47,5$.

19. Biswas R., Sahadath H, Mollah A. S. and Huq M. F. (2016) Calculation of Gamma-Ray Attenuation Parameters for Locally Developed Shielding Material: Polyboron, Journal of Radiation Research and Applied Science, 9, 26-34.

20. Petersen G. M. and Carlsen B. W. (April 2019), Neutron Absorber Considerations for the DOE Standardized Canister, INL/CON-1852108-Revision-0.

21. Shaimaa Hafez, El-Kameesy S. U., Eissa M. M., Elshazly R. M., El Fawkhry M. K., Aly Saeed (2019) The Effect of Boron and Titanium Addition on the Behavior of Steel Alloys of Base Composition AISI304Mo as a Nuclear Radiation Shielding Material, Arab $J$. Nucl. Sci. Appl., 52, 36-44. 